\author{
ISSN: 2146-3042
}

DOI: $10.25095 /$ mufad.510596

\title{
Kripto Değişim Araçlarının Muhasebeleştirilmesi
}

\section{$\ddot{O Z E T}$}

Cryptocurrency kelimesi şifreli para veya şifreli değişim aracı olarak ifade edilebilir. Özellikle 2017 yılında para birimleri karşısında çok yüksek oranlarda değer kazanmasiyla birlikte, devlet otoriteleri, düzenleyici kuruluşlar ve yatırımcıların dikkatini çekmiştir. Devletler bu işlem ve olayları kayıt altına alma, vergilendirme, finansal tablolarda sunumu, arkasinda herhangi bir devlet otoritesi veya düzenleyici kuruluş olmamast ve devletlerin para ve maliye politikaların etkileme ihtimali konulartyla ilgilenirken, yatırımcılar volatilitesinin yüksek olması, yaptıkları yatırımın güvence altında olmaması ve yatırımın finansal tablolara yansitılamaması konulariyla ilgilidirler.

Çalışmamızda öncelikle kripto değişim araçları incelenmiş, daha sonra bu araçların para, menkul kiymet veya emtia olarak tanımlanması ihtimalleri ele alınmıştır. Ayrıca bu araçların madenciliğini yapan, değişim aracı olarak kullanan, bu alım satımın yapan işletmeler için ülkemizdeki Muhasebe Sistemi Uygulama Genel Tebliğleri ve Uluslararası Muhasebe Standartları hükümleri doğrultusunda muhasebeleştirme ve finansal tablolarda sunum konuları ele alınmıştır.

Anahtar Kelimeler: Kripto Araçlar, Bitcoin, Finansal Tablolarda Sunum, Muhasebe Sistemi Uygulama Genel Tebliğleri, Uluslararası Muhasebe Standartları

JEL Sinıflandırması: M41, M48, E42

\section{Accounting For Cryptocurrencies}

\section{ABSTRACT}

The cryptocurrency word can be defined as an encrypted currency or encrypted exchange. Especially in 2017, with value increases at high rate against other currencies, has attracted the attention of State authorities, regulatory agencies and investors. While states are interested in recording these transactions and events, taxation, presentation in financial statements, and not being any state authority or regulatory body behind them, and the possibility of affecting the monetary and fiscal policies of states; investors are interested in the high volatility, the lack of guaranteed their investments and are not included in the financial statements.

In our work, firstly the cryptocurrencies were examined and then the probabilities of defining these instruments as "money", "securities" or "commodities" are discussed. In addition, issues of the accounting of these instruments and their presentation in the financial statements are tackled for bussiness engaged in the mining of these tools, use them as a means of currency in their trade and engaged in trading in these instruments in accordance with international accounting standards and general communiqués of the application of accounting system in our country.

Keywords: Cryptocurrencies, Bitcoin, Presentation in Financial Tables, General Communiqué of Accounting System Implementation, International Accounting Standarts.

Jel Classification: M41, M48, E42

\footnotetext{
* Doç. Dr., Kütahya Dumlupınar Üniversitesi, Uygulamalı Bilimler Yüksekokulu, selcuk.yalcin@dpu.edu.tr, ORCID ID: 0000-0002-9402-7524
} 


\section{GİRIşs}

Blokchain verilerin saklandığg, daha sonra ulaşılarak görülebildiği bloklardan oluşan ve sisteme dahil kullanıcıların verilerin doğruluğu konusunda mutabakatıyla yeni blokların eklendiği veri zinciridir. Zincirde yer alan her blok kendisinden önceki blok verilerinin özetini içerir. Böylece zincirdeki bir halka üzerindeki verilerin dışarıdan müdahale ile değiştirilmesi imkânsız hale gelir. Herhangi bir halkada yer alan veriler değiştirilmiş olsa da, halkanın geri çağırılması sırasında zincirdeki diğer kopyalarıyla karşılaştırılarak otomatik olarak eski haline gelir. Diğer taraftan veriler bloklara şifrelenerek kayıt edildiği için anahtara sahip olmayan birisi bloku açamaz. Böylece sisteme dışından müdahale önlenmiş olur.

Günümüzde blokchain teknolojisi elektronik ticaret, para transferi, verilerin gizliliğinin korunması, depolanması ve paylaşılması ile sözleşmelerin saklanması gibi pek çok amaçla kullanılabilmektedir.

Zincire halka eklenmesi ve mutabakat işlemleri madencilik olarak adlandırılmaktadır. Madencilik yapmanın bir ödülü vardır. Günümüzde Blokchain teknolojisini kullanan ve bitcoin, ethereum, ripple ve litecoin gibi alternatif kripto değişim araçlarını dağıtan 1.300 kadar zincir bulunmaktadır. Örneğin Bitcoin'de madenci zincirde yer alan en son halkanın özetini Blokchain üzerinde çalışan, ücretsiz olarak edinilebilen, bir algoritma üzerine aktarır ve bu algoritmayı çalıştırarak bir problemin çözümünü yapar. Çözümün doğruluğunun mutabakatı diğer madenciler ile sağlandıktan sonra yapılan çözüm zincire eklenir. Zincire eklenen bu halka önceki halkaların özetini de içeren yeni bir halkadır. Madenciler sonraki halkayı ekleyebilmek için çözümlemeye önceki halkanın özetinden başlamak zorundadır. Böylece her bir halkanın boyutu kendinden önceki tüm halkaların özetlerini içerdiğinden, öncekinden daha büyük olacaktır. Diğer taraftan zincire halka eklemeyi başaran madenci 12,5 bitcoin sahibi olmaktadır.

Günümüzde bazı işletmeler yeni müşteri kazanma ve müşteri memnuniyeti sağlamak amacıyla Bitcoin benzeri bu araçları ödeme aracı olarak kabul etmeye başlamışlardır. Bu işletmeleri, ülkemizdekiler de dahil olmak üzere, "https://coinmap.org" benzeri internet sitelerinden bulmak mümkündür. Diğer taraftan bu araçlar sanal piyasalarda alınıp satılmakta, birbirleriyle değişimi yapılmakta ve bunlar üzerine vadeli işlemler yapılmaktadır. Böylece Blokchain teknolojisi, ortaya çıkış amacının ötesine geçmiş ve zincirin ödül kazanmak için kullanılması ve kazanılan ödülün kullanım alanları daha fazla tartışılmaya başlanmıştır.

$\mathrm{Bu}$ çalışmanın amacı kesinlikle kripto araçlara dikkat çekmek ve okuyucuyu bu araçlara yönlendirmek değildir. Ancak bu araçlar ticari hayata girmiştir. Bu araçlarla yapılan işlem ve olayların muhasebe kayıtlarına ve finansal tablolara aktarılması bir gerekliliktir. $\mathrm{Bu}$ amaçla çalışmamızda öncelikle bu araçların para, menkul kıymet yada emtia olarak kabul edilmesi konusundaki tartışmalar ortaya konmaktadır. Daha sonra bu araçların vergi kanunları doğrultusunda yapılandırılan Muhasebe Sistemi Uygulama Genel Tebliğleri ve Uluslararası (Türkiye) Muhasebe Standartları yönünden durumları tartışılmıştır. Son olarak madencilik yapan, bu araçları alım satımda kullanan ve ticaretini yapan işletmeler açısından bu işlem ve olayların muhasebe kayıtlarına ve finansal tablolara aktarılması ele alınmaktadır. 


\section{BLOKCHAIN TEKNOLOJISI}

Blockchain dijital ekonominin yıkıcı bir ürünüdür. Çoğunlukla Bitcoin ile eşanlamlı kabul edilmesine rağmen Blockchain, Bitcoin veya başka herhangi bir şifreleme özelliği değil, temel bir teknolojidir. Daha spesifik olarak, sanal bir para birimi söz konusu olduğunda, Blockchain sanal para birimiyle ilgili tüm işlemlerin sayısal bir kayıt tutucusu olarak kullanılan pek çok uygulamadan biridir. Bir Blockchain, kriptografik olarak bağlantılı veri blokları zincirinden oluşur. Bloklar, kriptografik karmaları kullanarak bir sırayla zincirlenir. Bir karma, belirli bir mesaj veya belgeden türetilmiş bir uzunluk numarasıdır. Her blok üç ana bileşenden oluşur:

(1) Blok Veri: Bir dizi mesaj veya işlem;

(2) Zincirleme Hash: Hemen önceki bloğun karma değerinin bir kopyası; ve

(3) Blok-Hash: Veri bloğunun veya mesajlarının hesaplanan karma değeri ve 2 'de zincirleme karma değeri (Leon vd, 2017: 289).

Günümüzde bu teknolojilere bankacılık, finans, sigorta, sağlı, kamu yönetimi ve mesleki hizmetler gibi birçok alanda kullanılabileceği için yoğun ilgi gösterilmektedir. Bununla birlikte, Blockchain hala yeni bir teknolojidir ve değişmeye ve gelişmeye devam etmektedir. Özellikle bankacılık dışındaki sektörlerin Blockchain'in ve bunun nasıl çalıştı̆̆ının farkında olmaması ve bu konularda bir anlayış eksikliği olması nedeniyle, halen bu yükselen ve büyüyen teknolojinin değerini netleştirme ihtiyacı devam etmektedir (Mourouzis ve Chrysostomos, 2017: 2).

Blockchain teknolojisi, Nakamoto (2008) tarafindan tasarlanmış ve başlatılmıştır. Satoshi Nakamoto'nun bir insan, grup veya bilgisayar sistemi olduğu konusunda kesin kanıt yoktur. Nakamoto'ya atfedilen, 2008 yılında ve nerede basıldığı belli olmayan ve internette halen ulaşılabilen bir makalede sistemin detayları açıklanmaktadır. Nakamoto (2008) makalesinde internet üzerinden yapılan ticarette ödemeler için finansal kurumlara güvenilmesi zorunluluğunun bulunması, bunlarla ilgili işlem maliyetlerinin yüksekliği, işlemlerin geri çevrilmesinde yaşanan sorunlar ve ödemelerin garanti edilmesindeki güçlükleri sıralamıştır. Daha sonra ise ihtiyaç duyulan şeyin güven yerine şifreleme kanıtı üzerine kurulu, istekli herhangi iki tarafın güvenilir bir üçüncü şahsa ihtiyaç duymadan birbirleriyle doğrudan işlem yapmasına izin veren bir elektronik ödeme sistemi olduğunu belirtmiş ve sistemin çalışma prensiplerini ortaya koymuştur.

Blockchain ağları temel olarak değer içeren verilerin (para, kimlik, değerli kâğıtlar gibi) güvenli ve emin bir şekilde depolanması ve yönetilmesi için tasarlanmış bir teknolojidir (Usta ve Doğantekin, 2017: 123). Nakamoto merkezi olmayan, kamuya açık ve kriptografik açıdan güvenli bir dijital para sistemi oluşturmak için bir blok zinciri kullanmıştır. Bitcoin adlı sistem peer to peer dijital para ticaretine olanak tanır. $\mathrm{Bu}$, işlem emniyetini korurken finansal aracılara olan ihtiyacı ortadan kaldırır (Dai ve Vasarhelji, 2017: 6). Peer to peer kavramı eşten eşe anlamındadır. Bir ağ sisteminde eşler, internet aracılığıyla bağlanan bilgisayar sistemleridir. Dosyalar sistemler arasında herhangi bir merkezi bir sunucuya ihtiyaç olmadan direkt olarak paylaşılabilir. Bir başka deyişle eşten eşe ağındaki her bir bilgisayar bir dosya sunucusu ve bir istemci olur (https://techterms.com). Bu da işlemlerin herhangi bir 
otorite tarafindan takip edilmesini imkânsız hale getirmektedir. Buradaki her bir işlem, sistemdeki katılımcıların çoğunluğunun oybirliğiyle doğrulanır. Buna mutabakat işlemi denir. Veri bir kez girildiğinde asla silinemez. Veri tabanı, yapılan her işlemin kesin ve doğrulanabilir bir özetini içerir. Blockchain yaklaşımında verilerin saklandığı yapılar blok olarak adlandırılır. Ve bu blok yapıları bir zincir şeklinde (zaman açısından doğrusal bir dizi yapısında) düzenlenir. Bu zincir kapsamındaki ilk blok yapısına "genesis" (başlangıç) blok denir (Usta ve Doğantekin, 2017: 123-124).

Şu andaki en popüler Blockchain platformu olan Bitcoin üzerinde proof of work mutabakat yaklaşımı kullanılmakta ve ilgili süreç madencilik (mining) olarak adlandırılmaktadır (Usta ve Doğantekin, 2017: 128). Madencilerin her 10 dakikada bir blok mutabakatı sağlaması zincire blok eklemesi, önceki bloklardaki tüm ilgili işlemlerin değiştirilemeyeceği anlamına gelir. Bu güvenlik ve gizliliği arttırır (Boomer, 2016: 26). Zincire her eklenen blok kendisinden önceki tüm işlemlerin özetini (hash) içerdiğinden ve zaman bilgisi kullandığından zincirdeki bilgileri değiştirmek mümkün değildir. Değiştirilse bile geri çağırıldığında sistemde bulunan binlerce kopyasından veri eski haline dönmektedir. $\mathrm{Bu}$ yapıda kötü niyetli birisinin, Blockchain ağı üzerinde hedef aldığı bir blok içeriğini değiştirebilmesi için hem hedef bloğu hem de ondan sonra gelen tüm blokları değiştirmesi gerekmektedir. Blok üretiminin sürekliliği (saldırgan değişim yaparken Blockchain'e yeni blokların katılıyor olması) ve blok üretim yaklaşımlarının yapılarından dolayı bu senaryo teorik olarak gerçekleştirilebilecek olsa da pratikte gerçekleştirilmesi normal koşullarda mümkün görülmemektedir (Usta ve Doğantekin, 2017: 127).

Blokchain sisteminde veri, sayısı milyonları bulan makineler üzerinde yer alır. Bir veriye ulaşmak istendiğinde sistem en optimum düzenleme ile bu veriyi farklı makinelerden alabilecek şekilde yönlendirir. Veriyi çeken kullanıcı aynı zamanda diğer kullanıcılar için de veri kaynağıdır. Dolayısıyla sistemden faydalanan kullanıcı aynı zamanda sisteme hizmet etmektedir.

Şifreleme, herhangi bir veri kümesini bir kural yapısı kullanarak rastgele görünen bir veri kümesine dönüştürür. $\mathrm{Bu}$ rastgele gibi görünen veri kümesi, şifreleme yapılırken kullanılan anahtar ile sahibi için orijinal anlamlı haline geri dönüştürülebilirken bu anahtara sahip olmayanlar için tekrar orijinal yapısına çevrilemez. Böylece şifrelenmiş veri nerede ve ne şekilde depolanırsa depolansın sadece anahtar sahibi tarafından anlamlı kalmaya devam edecektir (Usta ve Doğantekin, 2017: 42).

\section{KRIPTO ARAÇLAR}

Bitcoin, ilk olarak Nakamoto (2008) tarafından bir makalede özetlenen merkezi olmayan bir eşler arası kripto para birimi protokolüdür (Brandvold vd, 2015: 18). Bitcoin ve benzeri dijital para birimleri, temel algoritmalar ve güvenlik dijital şifreleme algoritmalarıyla yakından alakalı olduğu için kripto araçlar olarak anılabilir. Bir kamuya açık veritabanı her alım satımı kaydeder. Her bitcoin hareketi bir adresle ilişkilendirilir ve işlem, bir adresten diğerine geçişi gerçekleştirir. Bu veri tabanı blok zinciridir (Dwyer, 2015: 83). Blokchainde bir bloğun üretilebilmesi için sistem üzerinde zorluk seviyesi sisteme dahil olan mutabakat noktalarının sayısına ve bu bilgisayarların işlem gücüne bağlı olarak değişen bir matematiksel problemin çözüm kümesini bulmak gerekmektedir. Her bir blok üretiminde bloğu üreten noktaya sistem tarafından yine miktarı belirli kriterlere bağlı değerde Bitcoin verilmektedir. 
Bitcoin, her başarılı blok üretimi için 12,5 BTC ödüllendirme yapmaktadır (Usta ve Doğantekin, 2017: 135).

Blockchain ağı üzerinde Bitcoin ile benzer tasarıma sahip "alt-coin” (alternative coin) adı verilen pekçok kripto araç bulunmaktadır. Günümüzde kripto araçlar, piyasa işlevi gören internet siteleri üzerinde alınıp satılabildiği gibi birbiri arasında da değişimi mümkündür. Tüm dünya çapında bu araçları ödeme aracı olarak kabul eden, değişimini yapan kişi ve organizayonlar coinmap.org benzeri internet adreslerinden takip edilebilmektedir. Yine worldcoinindex.com sitesinde 1.641 adet kripto aracın takibi yapılmaktadır.

Bir bitcoin bir dijital imza zincirinden oluşmaktadır. Her Bitcoin sahibi bir açı anahtar bir de özel anahtara sahiptir. Bu anahtarlar bir dosyada saklanmaktadır. Eğer bu dosya bilgisayardan silinirse ya da kaybedilirse bununla bağlantılı bitcoinler de kaybedilmiş olacaktır. Bitcoin transferinin yapılması için teknik olarak, Bitcoin gönderilmek istenen kişinin Bitcoin gönderecek kişiye açık anahtarını göndermesi gerekmektedir (Yüksel, 2015: 200). Bitcoin kullanıcının bilgisayarına kurulan açık kaynak bir yazılımın çalıştırılmasıyla kullanılır ve eldeki Bitcoin'ler sanal cüzdanlarda saklanır. Sistemin bir sunucu yerine dağıtık ağ üzerinde çalışması ve açık kaynak kodlu olması, sisteme müdahalenin önündeki en büyük engeldir.

Parasal para birimlerinin aksine, şimdiye kadar elde edilen veya oluşturulacak toplam bitcoin miktarı sınırlandırılmıştır (Brandvold vd., 2015: 18). Bitcoin, 2040 yılına kadar oluşturulması beklenen 21 milyon sabit bir sınırla tasarlanmıştır (Nian ve Lee, 2015: 19). Bitcoin sayısının sınırlandırılması değerli madenlere benzetilmek amacıyla getirilmiş bir uygulamadır. $\mathrm{Bu}$ sayı tamamlandıktan sonra madencilik faaliyetinin son bulacağ belirtilmekle birlikte, sisteme dişarıdan müdahale edilerek, sayının arttırılamayacağ konusunda kesinlik yoktur. Özel donanımlarıyla yazılımı çalıştıran madenciler bir taraftan Bitcoin kazanırken; diğer taraftan ağın gücüne güç katma ve koruyup geliştirme konusunda katkı sunmaktadır. Madencilik sadece yeni Bitcoin kazanmak için değil, aynı zamanda işlemlerin blok zincirine eklenmesi ve ardından teyit edilmesi için gerekli bir süreç olduğundan önemlidir. Doğrulama süreci, sadece meşru işlemlerin blok zincirinde doğrulanmasını ve kaydedilmesini sağlayan, hesaplama açısından yoğun bir işlemdir. İşlemlerin gerçekleşmesi ve işlemlerin kaydedilmesi için hesaplama gücünü sağlayan ağdır. Madencilik aslında bir matematiksel işlemdir (Nian ve Lee, 2015: 19).

Bitcoin'in diğer bir özelliği de, merkez bankasının fiyat para birimlerinde olduğu gibi paranın değerinin güvence altına aldığına güvenmek yerine dağıtık ağ tarafından sağlanan şifreli delillerin doğru olduğuna inanılmasıdır (Brandvold vd, 2015, 18). Kullanılan şifreleme yöntemlerinin sağladığı güvenlik kapsamında dijital paranın taklit edilmesi, izinsiz kullanılması ve kural dışı bir şekilde oluşturulması mümkün olmamaktadır (Usta ve Doğantekin, 2017: 62).

Bitcoin 22.05.2018 tarihi itibariyle kripto araçların değerlerini ve işlem hacimlerini izleyen http://coinmarketcap.com/ sitesinden aldığımız verilere göre en büyük hacimli kripto araçtır. Dolaşımda bulunduğu varsayılan $17.046 .762^{1}$ adet bitcoinin değeri $(1 \mathrm{BTC}=8.402$

\footnotetext{
${ }^{1}$ https://coinmarketcap.com/22.05.2018
} 
$\left.\$^{2}\right)$ 143.226.894.324 \$ ve son 24 saatteki işlem hacmi 5.186.660.000 \$'dir ${ }^{3}$. TC Merkez bankası döviz satış kuru $1 \$=4,5684 \mathrm{TL}^{4}$ olduğuna göre bitcoinin piyasa büyüklüğü 654.317.744.030 TL olarak hesaplanabilir.

Grafik 1. Bitcoin Fiyat hareketleri

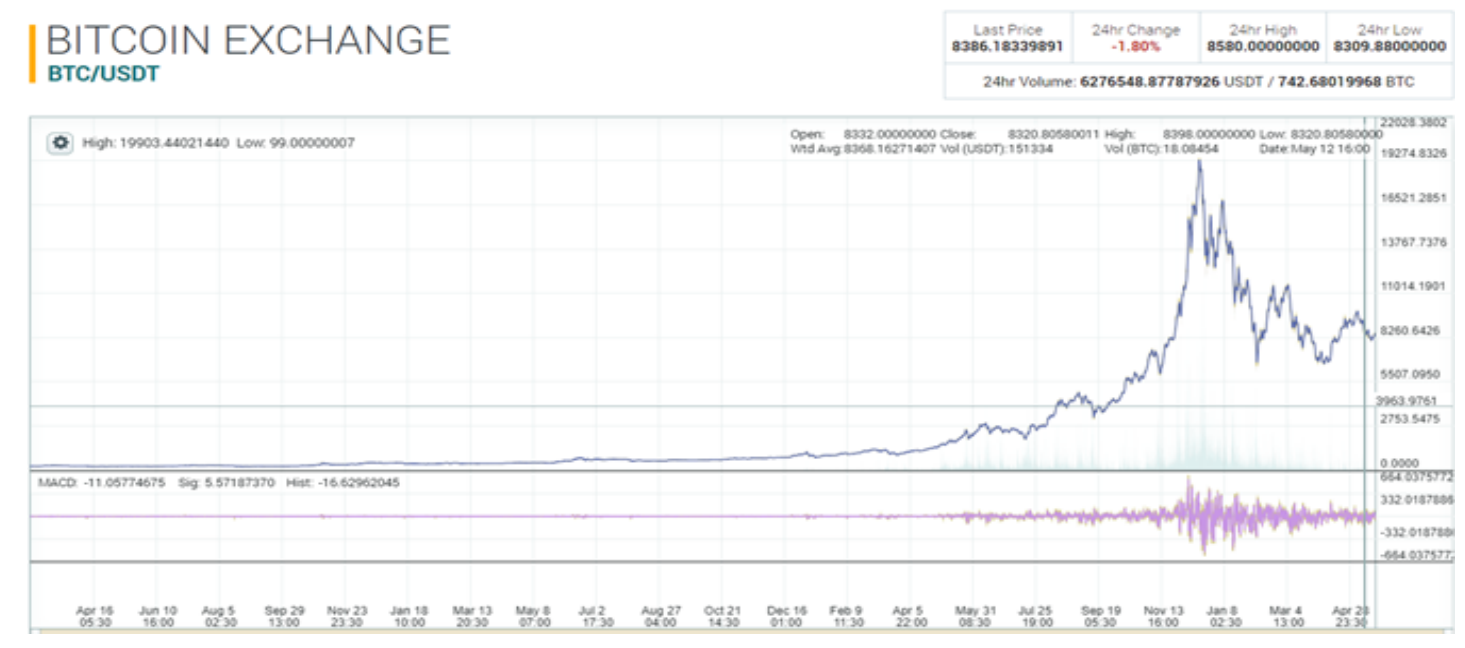

Kaynak: https://poloniex.com/exchange\#usdt_btc/22.05.2018

Sayıları 7 bin 500'ü geçen kripto para borsalarında TL ile işlem yapılabilen dört borsa bulunur. Türkiye'de Bitcoin ile işlem yapan kullanıcı sayısı son 6 ayda 9 binden 42 binin üzerine çıkmıştır. TL Bitcoin borsaları ortalama yüzde 0.4 'lük işlem komisyonu ve $3 \mathrm{TL}+$ KDV'lik para çekme ücretleri almaktadır (https://www.memurlar.net).

Bugün için bitcoin yatırımlarının ve işlemlerinin boyutu, diğer varlıklara göre daha küçük olduğu için, finansal veya parasal istikrar için acil bir risk veya tehlike görülmemektedir. Bununla birlikte, bu sonuç işlem hacminin ve toplam piyasa değerinin daha önce açıklandığ 1 şekilde diğer piyasalar karşısında küçük olmasından kaynaklanmaktadır. Bitcoin veya benzeri sanal araçların kabulü küresel düzeyde önemli ölçüde artarsa, tüketicilerin ve üreticilerin davranışlarını etkileyebilir ve bunun sonucunda para politikasının önemi değişir. Bitcoinin merkezi olmayan doğası ve herhangi bir merkezi bankadan veya uluslarüstü otoriteden bağımsızlığı göz önüne alındığında, düzenleyici gözetim zor olabilir (Baur ve Hong, 2015: 10).

Kripto araçların en popüleri olan Bitcoin'in bile piyasa büyüklüğünün bu seviyelerde olmasına rağmen bu kadar gündemde olmasının pek çok sebebi vardır. Bunlar arasında fiyat dalgalanmasının çok fazla olması, 2017 yılında değerinin 20 katına çıkması ve 19.000 \$ seviyelerini görmesi, Kasım 2017 ortalarından Şubat 2018 ortalarına kadar 7.500 \$ seviyelerine kadar düşmesi, kısa sürede büyük kazanç veya kayıpların yaşanması, ulusal ve uluslararası denetim mekanizmalarının dışında yer alması, kayıt dışı işlemlerin kolayca

\footnotetext{
${ }^{2}$ https://poloniex.com/exchange\#btc_bch/22.05.2018

${ }^{3} \mathrm{https}: / /$ coinmarketcap.com/22.05.2018

${ }^{4}$ https://www.turkiye.gov.tr/doviz-kurlari/22.05.2018
} 
gizlenebilmesi, uluslararası sistemde yaşanan sorunlar ve bunlara bağlı olarak dolar benzeri para birimlerine olan güvenin azalışı sayılabilir.

Diğer taraftan The Economist dergisinin 1988 yılı 9 Ocak tarihli sayısında yer alan “Tek Dünya Parasına Hazır Olun” başlıklı yazı ve dergi kapağında yer alan temsili paranın üzerinde 2018 tarihinin yer alması kripto ödeme araçlarının uzun süreli bir hazırlığın sonucu olabileceği konusunda ipuçları sunmaktadır.

Ülkelerin bağımsızlıklarının en önemli göstergelerinden biri para basmaktır. Yine merkez bankaları para politikası araçlarını ülkelerin ekonomilerini yönlendirme amaçlarıyla kullanırlar. Ödeme aracı olarak para yerine kripto araçlarının kullanılmasıyla ülkelerin elinden bu yönetim aracı da alınmış olacaktır. Ayrıca kripto araçların merkezi otoriteler tarafından denetlenememesi yasa dışı faaliyetlerin gizlenebilmesine yardımcı olacaktır. Bir başka iddiaya göre kripto araçlar harcanarak yapılmış her işlemin şifrelenmiş olsa da bir yerlerde kayıt altına alınması, kişilerin özel hayatlarının gizliliğine yapılmış bir müdahale olarak düşünülebilir.

\section{KRIPTO ARAÇLARIN SINIFLANDIRILMASIYLA İLGILII TARTIŞMALAR}

Kripto araçların hukuki durumu, sahipliğin yetki ve sorumlulukları ile muhasebe açısından sınıflandırılması, değerlemesi, kazanç/kayıpların muhasebeleştirilmesi ve finansal tablolarda sunumu konusunda öncelikle bu araçların menkul kıymet, emtia veya para olarak kabul edilmesi hususları tartışmalıdır. Bu yüzden çalışmamızda kripto araçların hangi gruba dahil edilebileceği konusu incelenmiştir.

Konu ile ilgili olarak SPK, Maliye Bakanlığı, BDDK gibi kurumlar bu araçlarla ilgili çalışmalarını sürdürmektedir. Merkez Bankası bunun para olamayacağını, SPK ise menkul kıymet olarak değerlendirilemeyeceğini açıklamış durumdadır. Kripto araçların emtia olarak kabul edilmesi de gündemdedir.

\subsection{Menkul Kiymet}

Menkul kıymet, çıkaranın gelecekteki geliri veya varlıkları (finansal hak iddiası veya sahipliğine konu olan bir mülk parçası) üzerinde bir hak iddiasıdır (Mishkin, 2011, 3-4). Menkul kıymet, alacaklılık veya ortaklık hakkı sağlayan kıymetli evraktır (Şen, 2005: 5-6).

Menkul kıymetler: Para, çek, poliçe ve bono hariç olmak üzere; sertifikalarını,

1) Paylar, pay benzeri diğer kıymetler ile söz konusu paylara ilişkin depo

2) Borçlanma araçları veya menkul kıymetleştirilmiş varlık ve gelirlere dayalı borçlanma araçları ile söz konusu kıymetlere ilişkin depo sertifikalarını ifade eder (6362 Sayıl1 Sermaye Piyasası Kanunu, madde 3, prg. o1-2).

Menkul kıymetler, alacaklılık veya ortaklık hakkı sağlama yanında, belli bir meblağ temsil etme, yatırım aracı olarak kullanılma, dönemsel gelir getirme, misli nitelikte, seri 
halinde çıarılma ve ibarelerinin aynı olması ve şartlarının Kurulca belirlenmesi gibi özelliklere sahip olmalıdır (Şen,2005: 5)

6102 sayılı TTK'nın 7. bölümü "Menkul Kıymetler” başlığını taşımakta ve ilgili bölümde pay senetleri ve intifa senetleri işlenmektedir. Buradan TTK'nın sadece hisse ve borçlanma senetlerini menkul kıymetler kapsamında değerlendirdiği görülmektedir.

Yukarıda verilen açıklamalar doğrultusunda kripto araçları menkul kıymet olarak değerlendirmenin mümkün olmadığg söylenebilir. Bununla birlikte bu araçların bir araya getirilmesiyle bir varlığa dayalı menkul kıymet oluşturulması durumunda bu varlıklar menkul kıymetleştirilebilir. Bu durumda bile menkul kıymet, bu araçların kendisi değil, bunların yer aldığ 1 sepete ait paylar olacaktır. Diğer taraftan kripto araçlar vadeli işlemlere konu olduğunda, kripto araçlar değil, bu araçlar üzerine oluşturulan türev araçlar menkul kıymet olarak değerlendirilmelidir.

\subsection{Emtia}

Türk Dil Kurumu Sözlüğü’nde emtia "ticaret, mal" olarak tanımlanmaktadır. Emtia Arapça kökenli meta sözcüğünün çoğul halidir. Mallar anlamına gelir. Türkçe'de tekil ve çoğul, ticarete ve alım satıma konu olan bütün mallar için emtia kelimesi kullanılmaktadır. Petrol, altın, gümüş, platin, bakır, metal, mineral gibi değerli madenler; arpa buğday mısır, pirinç gibi temel gıda maddeleri ile soya fasulyesi, pamuk, kahve, şeker, kömür gibi bir başka ürünün üretiminde kullanılan hammaddeler emtia olarak isimlendirilir. Emtialar ayrıca borsada yatırım aracı olarak da işlem görmektedir. Bu piyasalara emtia borsası adı verilir. Ülkemizde Türkiye Odalar ve Borsalar Birliği’ne bağlı 113 adet emtia borsası faaliyet göstermektedir.

Muhasebede işletmenin üretim ve alım satım faaliyetlerine konu olan varlıklar emtia olarak nitelendirilebilir. $\mathrm{Bu}$ açıklamalardan sonra kripto araçların emtia olarak nitelendirilmesi mümkün görülmemektedir.

\subsection{Para}

TDK sözlüğünde para; "devletçe bastırılan, üzerinde değeri yazılı kâğıt veya metalden ödeme aracı, nakit" şeklinde tanımlanmaktadır. İktisatçılar, parayı (para arzı anlamına da gelebilir), mal ve hizmet karşıllı̆ı yapılan ödemelerde veya borçların geri ödemesinde kullanılan genel kabul görmüş herhangi bir şey olarak tanımlarlar (Mishkin, 2011: 49). Doktrinde paranın genel bir tanımı, mal ve hizmetlerin bedelinin ödenmesinde ve borçların ödenmesinde kullanılan ve genel kabul gören her şey olarak yapılmaktadır (Yüksel, 2015: 175). Paranın en kabul gören tanımı, "herkes tarafindan kabul edilen mübadele aracı" olduğunu vurgulayarak yapılan tanımdır (Dinler, 2003: 381). Parayı yalnızca nakit para olarak tanımlamak iktisatçılar açısından çok dar bir tanımdır. Çünkü satın alımlar karşılığında verilen çekler de ödeme olarak kabul edildiğinden üzerine çek yazılabilir mevduat hesapları da para olarak düşünülür. Hızlı ve kolay bir şekilde nakte veya çek hesabı mevduatına dönüştürülebildikleri takdirde vadesiz mevduatlar gibi diğer kalemler de para olarak işlev gördüğünden, paranın daha geniş bir tanımına gerek duyulur (Mishkin, 2011: 49). Paranın işlevleri/fonksiyonları; değişim/mübadele aracı olması, hesap birimi/değer ölçüsü olması ve tasarruf/değer biriktirme aracı olması şeklinde sayılabilir. Buna göre mal ve hizmetlerin satın 
alınmasında para bir değişim aracıdır (Yüksel, 2015: 175). Paranın üç temel işlevi, değişim aracı, hesap birimi ve değer depolamasıdır. Kavramsal olarak, bu üç fonksiyona hizmet eden herhangi bir belirteç para olarak kabul edilir. Zamanla, para olarak kullanılan simge emtia (arpa, kızılcık kabuğu, altın, gümüş vb.) ile hükümete (fiyat parası) ve şimdi de sanal verilere (dijital para birimi) ilişkin kâğıt notalarına dönüşmüştür (Seng ve Yew, 2015: 221).

Para ister deniz kabuğu, ister taş, altın veya kâğıt şeklinde olsun, herhangi bir ekonomide para üç fonksiyona sahiptir: Para bir değişim aracıdır, para bir hesap birimidir ve para bir değer saklama aracıdır (Mishkin, 2011: 50). Mübadele aracı olan paranın en önemli özellikleri arasında, toplumdaki herkes tarafindan kabul edilmesi, taşınmasının kolay olması, dayanıklı ve bölünebilir olması, kolay taklit edilememesi ve miktarının az olması sayılabilir (Dinler, 2003, 382). Standartlaştırılmış, taşınabilir, dayanıklı, bölünebilir ve ödeme için yaygın olarak kabul edilmelidir (Seng ve Yew, 2015: 222).

Günümüzde kripto araçlar değişim aracı olarak kabul edilmekte, hesap birimi olarak görülmekte ve değer saklama aracı olarak kullanılmaktadır. Diğer taraftan bazıları tarafından balon olarak nitelendirilse de pek çok kişi tarafından kabul edilmekte, taşınması kolay, güvenlik riskleri ve volatilitesinin yüksek olması nedeniyle nispeten dayanıklı ve bölünebilir, kolay taklit edilemeyen ve miktarı sınırlı araçlardır. Belirtilen özelliklerin hemen hepsine sahip olduğu düşünülürse kripto araçları para ve para yerine geçen araç olarak kabul etmek doğru bir yaklaşım olacaktır.

\section{KRIPTO ARAÇLARIN MUHASEBELEŞTIRILLMESI}

Kripto araçların para, menkul kıymet yada emtia olarak kabul edilmesi konusunda dünyada ve ülkemizde tartışmalar devam etmektedir. Tartışmalar sonucunda, kripto araçların nasıl sınıflandırılacağı konusunda, işletmelerde bunların yönetim modelinin esas alınmasının daha yararlı olacağı sonucuna varılmıştır. Örneğin üretim amacıyla kullanılan bir makine, üreten işletme açısından mamul, satışını yapan işletme için ticari mal, üretimde kullanan işletme için ise tesis makine cihaz olarak sınıflandırılır. Bu yüzden çalışmanın devamında kripto araçların varlık olarak sınıflandırılmasında, varlıkları aktifinde bulunduran işletmelerin bu varlıkları elinde bulundurma amacı ve bunların yönetim modeli esas alınmıştır. $\mathrm{Bu}$ çerçevede kripto araçların madenciliğini, ticaretini yapan ve değişim aracı olarak kullanan işletmeler açısından, bunların muhasebeleştirilmesi ve finansal tablolara alınması konuları irdelenmiştir. $\mathrm{Bu}$ amaçla Muhasebe Sistemi Uygulama Genel Tebliğleri ve Uluslararası Muhasebe/Finansal Raporlama Standartları doğrultusunda değerlendirmeler yapılmıştır.

Kripto araçlar ticari hayata girmiştir. Muhasebenin temel amacı bilgi kullanıcılarına işletmenin durumunu gerçeğe uygun şekilde sunmak olduğuna göre bu araçların muhasebeleştirilmesi, değerlemesi ve finansal tablolarda sunum ve açıklamaları konularının tartışılması ihtiyacı ortaya çıkmıştır.

Tartışılması gerekli konular arasında;

1. Kripto araçlar Blokchain teknolojisi ile oluşturulan algoritmaların çalıştırılması yoluyla blokların çözülmesinin karşılığında sistem tarafından verilen bir ödüldür. Blokların çözülmesi devasa bilgisayar sistemlerinin aylarca çalışmasını gerektirmektedir. Bunun 
maliyetinin hesaplanması, elde edilen kripto araçların muhasebeleştirilmesi ve finansal tablolarda sunumu nasil olacaktır?

2. Kripto araçların alım satımını yapan işletmelerde bu işlem ve olaylar nasıl muhasebeleştirilecek, finansal tablolarında sunum ve açıklamaları nasıl yer alacaktır?

3. Kripto araçları ödeme aracı olarak kabul eden işletmelerde bu işlemler nasıl muhasebeleştirilecek, finansal tablolarında sunum ve açıklamaları nasıl yer alacaktır?

4. Kripto araçlarla alım yapan işletmelerde bu işlem ve olaylar nasıl muhasebeleştirilecek, finansal tablolarında sunum ve açıklamaları nasıl yer alacaktır?

5. Kripto araçları yatırım ve riskten korunma amaçlı olarak elde tutan işletmelerde muhasebeleştirme, sunum ve açıklamalar nasıl yapılacaktır?

6. Muhasebe Sistemi Uygulama Genel Tebliğleri ve Uluslararas1 Muhasebe/Finansal Raporlama Standartları doğrultusunda bu işlem ve olaylar nasıl muhasebeleştirilecek? Her iki düzenlemeye göre düzenlenmesi gerekli finansal tablo setlerinde bu işlem ve olaylar nasıl sunulacak ve açıklamaları nasıl yapılacaktır? Her iki uygulamanın uyumlaştırılması nasıl yapılacaktır?

\subsection{MSUGT Açısından Kripto Araçlar}

1 Sira Nolu Muhasebe Sistemi Uygulama Genel Tebliği'nde, yapılan düzenlemenin muhasebe bilgilerinin karar alma durumunda bulunan ilgililere yeterli ve doğru olarak ulaştırılmasına yönelik olduğu belirtilmektedir. Bununla birlikte bu tebliğlerde pek çok konu vergi kanunları doğrultusunda düzenlenmiştir. $\mathrm{Bu}$ tebliğlerde kripto araçlarla ilgili bir düzenleme yoktur. Bu yüzden vergi kanunları çerçevesinde konu incelenecektir.

\subsubsection{Madencilik Yaparak Kripto Para Elde Eden İşletme}

Özel donanımlarıyla yazılımı çalıştıran madenciler bir taraftan Bitcoin kazanırken; diğer taraftan dağıtık ağın gücüne güç katma ve koruyup geliştirme konusunda katk1 sunmaktadır. Blokchain sisteminde veri, sayısı milyonları bulan makineler üzerinde yer alır. Bir veriye ulaşmak istendiğinde sistem en optimum düzenleme ile bu veriyi farklı makinelerden alabilecek şekilde yönlendirir. Veriyi çeken kullanıcı aynı zamanda diğer kullanıcılar için de veri kaynağıdır. Madencilik sadece yeni Bitcoin kazanmak için değil, aynı zamanda işlemlerin blok zincirine eklenmesi ve ardından teyit edilmesi için gerekli bir süreç olduğundan önemlidir. Dolayısıyla sistemden faydalanan kullanıcı aynı zamanda sisteme hizmet sunmaktadır. Sistemde blokların çözülmesi devasa bilgisayar sistemlerinin aylarca çalışmasını gerektirmektedir. Bu işlem elde edilebilecek, sınırlı sayıdaki ödül azaldıkça daha zorlaşacak şekilde yapılandırılmıştır.

Elde edilen ödül verilen hizmetin karşıllğı olduğuna göre, işletme için faaliyet geliridir. Böylece elde edilen ödüller satış gelirlerine alınırken; bunun için katlanılan maliyetler de hizmet üretim maliyetleri olacaktır. Bu çerçevede sunulan hizmetlerin maliyeti; direkt işçilik giderleri ve hizmet üretimiyle doğrudan ilişkili elektrik ve amortisman gibi genel üretim giderlerinden sistematik bir şekilde dağıtılan tutarlardan oluşacaktır. Ayrıca elde edilen kripto araçlar, günümüzde kolaylikla Türk Lirasina çevrilebildiği de düşünüldüğünde, Diğer Hazır Değerler arasında raporlanabilecektir.

Değerleme gününde elindeki kripto araçlara VUK 280. madde hükmü uygulanacaktır. Buna göre değerleme borsa rayici ile yapılacaktır. Borsa rayicine karar verilmesi konusunda 
muvazaalı hareketler olduğu anlaşılırsa alış bedelini esas alacaktır. Yabancı paranın borsada rayici yoksa değerleme kuru Maliye Bakanlığ tarafindan tespit edilecektir. Maliye Bakanlığı'nın kur ilan etmediği durumlarda TC. Merkez Bankası tarafından ilan edilen kurlar esas alınacaktır. Ortaya çıkan değerleme farkı kambiyo kar/zararı olarak kayıtlara alacaktır.

Böylece kripto araçların para olarak kabul edilmesi durumunda bunların ticaretinin yapıldığ 1 borsalarla ilgili düzenleme yapılması gereği ortaya çıkacaktır. Diğer taraftan kripto araçların volatiletesinin yüksek olması borsa değerinin belirlenmesinde ortaya çıkacak en önemli problemdir. Bunun Maliye Bakanlığı'nın kur ilan etmesiyle aşılabileceği düşünülebilir.

Diğer taraftan madencilik faaliyetinin sonucu elde edilen kripto araçlar yasal otorite tarafindan emtia olarak kabul edilirse alım satımında KDV uygulanması gerekecektir. Ayrıca her durumda elde edilen gelirler dolayısıyla gelir/kurumlar vergisi doğacaktır.

\subsubsection{Tahsilat veya Ödeme Aracı Olarak Kullanan İșletme}

Sattığı mal veya hizmet karşılığında kripto araç kabul eden işletme için kripto araç bir tahsilat aracıdır. Bu yüzden satıştan elde ettiği kripto aracı nakit benzerleri arasına alacak ve burada raporlayacaktır. Satış ve kripto aracın alınmasıyla ilgili verilen komisyon ve nakde çevirme giderleri pazarlama satış dağıtım giderleri arasına alınacak ve raporlanacaktır. Bununla birlikte vergi kanunlarındaki belirsizlikler ve volatilitesinin yüksek olmasından dolayı bunu kısa sürede nakde çevirecektir. Vadeli satışı, volatilitenin yüksek olduğundan, ticari gerekçelerle kabul etmemeyi tercih etmekle birlikte, satış ile tahsilat tarihleri arasındaki kur farklarını kambiyo kar/zararı gibi değerlendirecektir. Değerleme gününde elindeki kripto araçları VUK 280. madde hükmüne göre borsa rayici ile değerleyecektir.

Alımları karşılığında ödemelerini kripto araçlarla yapan işletme aldığı varlığın değerini kripto aracın o andaki kripto araç kuruyla Türk Lirasına çevirerek belirleyecek, kripto araçla ilgili işlem maliyetleri ve komisyonları da ilgili varlığın maliyetine ekleyecektir. Elinde tuttuğu kripto araçlardaki kur farklarını, kripto araç üzerinden alacak ve borçlarını da yine VUK'un 280 maddesi doğrultusunda değerleyecektir.

\subsubsection{Kripto Araç Alım Satımını Yapan İşletme}

Kripto araçların alım satımını yapan işletmeleri döviz alım satımına yetkili müesselere benzetebiliriz. Türk Parasının Kıymetini Koruma Hakkında 32 Sayılı Kararın 2. Maddesi "o" bendinde yetkili müesseseler "Bakanlıkça tespit edilen usul ve esaslar çerçevesinde dövize ilişkin işlemler yapmasına izin verilen ve kıymetli maden, taş ve eşyalara ilişkin işlemler de yapabilen anonim şirketler" olarak tanımlanmaktadır. Kararda belirtildiği üzere anonim şirket olarak kurulmak zorunda olan bu işletmeler 5520 sayılı Kurumlar Vergisi Kanunu 1. Maddesi uyarınca kurumlar vergisi mükellefidirler.

Yetkili Müesseselerin esas faaliyet konuları arasında döviz (efektif) alım satımı yer alır. Dolayısıyla kripto araç alım satımı yapan işletmeler için bu araçlar emtia niteliğindedir. Bunların satışından elde edilen gelirler esas faaliyet gelirlerini oluştururken, bu faaliyetlerle ilişkilendirilebilen giderler ise faaliyet giderlerini oluşturur. İşletmenin kripto arçlarının 
dönem sonu değerlemesinde VUK 280. madde hükmü uygulanacaktır. Dönem sonu stokların değeri tespit edildikten sonra satılan döviz maliyeti bulunarak kâr hesaplanacaktır.

Komisyon karşılığında kripto araçların alım satımında aracıllk yapan işletmeleri aracı kurumlara benzetebiliriz. Bu doğrultuda işletmenin faaliyet gelirleri aldı̆̆ 1 komisyonlardan oluşurken, faaliyet giderleri bu işlerle ilişkilendirilebilen giderlerden oluşacaktır.

Yasal otorite kripto araç alım satım ve aracılık faaliyetleri yapan işletmelerin halen yetkili müessese veya aracı kurum olarak belirlememiştir. Eğer bu şekilde tanımlanırsa, 3065 Sayılı Katma Değer Vergisi Kanunu 'nun 17.maddesinin 4. fikrasının "e" ve "g" bentleri uyarınca yetkili müesseselerin efektif alım satımları Katma Değer Vergisi'nden istisna edilmiş ve Banka Sigorta Muameleleri Vergisi kapsamına alınmıştır. Benzer uygulamalar kripto araç alım satımı yapan işletmeler için de uygulanabilecektir.

\subsection{Uluslararısı Muhasebe/Finansal Raporlama Stantardaları Açısından Kripto Araçlar}

Uluslararası Muhasebe Standardı: Muhasebe Politikaları, Muhasebe Tahminlerinde Değişiklikler ve Hatalar Standard, belirli bir işleme uygulanan mevcut bir standart veya yorum bulunmadığında, geliştirilen muhasebe politikasının, hem ilgili hem de güvenilir bilgiler sunması gerektiğini belirtmektedir. Bunu başarmak için, önce benzer konularla ilgilenen UFRS'deki gerekliliklere atıfta bulunulmalıdır. Aksi takdirde, bir "varlık", "borç", "özsermaye", "gelir" ve "masraf" tanımlamasına bakarak, Kavramsal Çerçeveye danışılmalıdır (Ram vd., 2016: 8).

Kavramsal çerçevenin 4.4 maddesi (a) bendinde "Varlık, geçmişte olan işlemlerin sonucunda ortaya çıkan ve halihazırda işletmenin kontrolünde olan ve gelecekte işletmeye ekonomik fayda sağlaması beklenen değerler” olarak tanımlanmıştır. Kripto araçlar burada belirtilen özelliklerin tamamını karşılamaktadır. Kripto araçların işletmenin kontrolünde olduğuna ilişkin kanıt olduğunda veya yönetim amaçları doğrultusunda kullanıma uygun olduğunda kripto araçlar varlık olarak tanınmalıdır. Kripto araçların fiyatlarındaki oynaklık varlığın tanınmasını engellememelidir.

Bitcoin maliyeti ile tanınmalıdır. Bitcoin'in defter değeri pazar fiyatını aşmamalı ve gerektiğinde değer düşüklüğ̈̈ açısından test edilmelidir. Bitcoin'in piyasa fiyatındaki artışların gerçekleşmeden muhasebeleştirilmesi uygun olmayabilir. Bu gerçekleştirilmemiş kazançların tanımlanmasına neden olabilir. Bitcoin'in piyasa değerinde gerçekleşen veya gerçekleşmemiş değişiklikler finansal tablo dipnotlarında belirtilmelidir (Ram vd, 2016: 15-16).

Bununla birlikte Bitcoin nakit, nakit benzeri varlık, maddi olmayan varlık veya yatırım olduğu konusu tartış̧labilir (Raiborn ve Sivitanides, 2015: 27). UMS 32 Finansal Araçlar: Sunum Standardı Madde 11'de Finansal araç: "Bir işletmenin finansal varlığı ile diğer bir işletmenin finansal borcunda ya da özkaynağa dayalı finansal aracında artışa neden olan herhangi bir sözleşmedir." şeklinde tanımlanmış; nakit ve nakit benzerleri finansal araçlar arasında sayılmıştır. Para (nakit) bir finansal varlıktır; çünkü bir değişim aracını temsil eder ve dolayısıyla bütün işlemlerin ölçülmesi ve finansal tablolara yansitılmasında esas teşkil eder. Bir banka ya da benzeri bir finansal kuruluş nezdindeki nakit mevduat bir finansal varlıktır, çünkü sahibine, sözleşmeden doğan, kuruluştan nakit çekme veya bakiyesine 
karşılık kredi veren lehine bir finansal borcun ödenmesinde kullanılacak çek veya benzer bir araç keşide etme hakkını temsil eder (UMS 32, Uygulama Rehberi UR3).

UMS 7 Nakit Akış Tabloları Standardı Madde 6'da nakit: işletmedeki nakit ile vadesiz mevduatı; nakit benzeri: tutarı belirli bir nakde kolayca çevrilebilen kısa vadeli ve yüksek likiditeye sahip ve değerindeki değişim riski önemsiz olan yatırımları, şeklinde tanımlanmıştır. Belirtilen tanımlamalar doğrultusunda kripto araçları ödeme veya tahsilat amaçlı olarak kabul eden işletmeler açısından bu araçlar nakit benzeri olarak değerlendirilebilir. Bununla birlikte UMS 7 Nakit Akış Tabloları Standardında nakit benzeri "değerindeki değişim riski önemsiz olan yatırımlar" ş̧eklinde ifade edilmiştir. Bu yönüyle kripto araçlar standardın nakit benzeri tanımının dışına çıkmaktadır. Ancak ödeme aracı olarak kabul edilen kripto araçları standarda göre bir başka şekilde sınıflandırmak zor görülmektedir. Ayrıca nakit olarak kabul edilmekle birlikte değerlerindeki değişim riski yüksek pek çok ülke para biriminin varlığı da düşünülmelidir.

Nakit olarak değerlendirilmek için, bunun para olması ve bir değişim sürecinde kullanılmaya hazır durumda olması gerekir. Nakit, değişimin standart ortamı olarak kabul edilir ve diğer bütün varlıkların ölçülmesi ve muhasebeleştirilmesi için temel olarak belirlenmiştir. Birçok şirketin halen borsa değişim sürecinde Bitcoin'leri kabul etmediği göz önüne alındığında nakit sınıflaması gerçekçi değildir (Raiborn ve Sivitanides, 2015: 27-28). Diğer taraftan bu anlayışa göre konvertibilitesi olmayan para birimlerinin de nakit olarak kabul edilmemesi gerekir. Oysa bu para birimleri de nakit olarak kayıtlara alınmaktadır.

Bitcoin bir devlet tarafından ihraç edilmiş ve çeşitli para birimleri cinsinden düzenlenmiş gerçek para karşıllğı olarak değiştirilebilse bile, Bitcoin'in "oldukça likit" olduğunu söylemek zor olabilir. Bitcoin, Birleşik Devletler'de veya yurtdışında çoğu ülkede tipik bir banka veya tasarruf kurumuna yatırılamaz. Bitcoin ayrıca, çoğu ATM'de nakde çevrilemez. Böyle sınırlı bir erişim, "oldukça likit" kavramını engellemektedir. Bitcoin kolayca bilinen bir nakit karşıllı̆̆1 olarak değiştirilmesine gelince, Bitcoin'in gerçek bir para birimine göre piyasa değeri dalgalanmaları, bu kavramdan şüphe uyandıracaktır (Raiborn ve Sivitanides, 2015: 28)..

Bitcoin sanal olmasına ve üretilen bazı sınırlı sayıda madeni paranın haricinde gerçek bir fiziksel varlığa sahip olmamakla birlikte, maddi olmayan varlık sınıflandırması herhangi bir kripto araç için uygun değildir. Maddi olmayan duran varlıklar, özellikle finansal araçları kapsam dışı bırakmaktadır (Raiborn ve Sivitanides, 2015: 28).

Bitcoin para olarak görülemezken, bir finansal döviz aracı olarak görmezden gelinemezler. Bunların hepsi göz önüne alındığında Bitcoin için makul varlık sınıflandırması, kısa veya uzun vadeli bir yatırımdır. Bitcoin'in yatırımlar olarak tutulması, alındıklarında değerleriyle kaydedilmesini gerektirir (Raiborn ve Sivitanides, 2015: 28).

TFRS 9 Finansal Araçlar (2017 sürümü) madde 4.1.1'de finansal varlıkların sınıflandırılması konusunda finansal varlıkların yönetimi için işletmenin kullandığı iş modeli ve finansal varlığın sözleşmeye bağlı nakit akışlarının özelliklerinin esas alınması gerektiği belirtilmiştir. 
$\mathrm{Bu}$ itibarla varlıkların sinıflamasında yönetimin bu varlıkları elde tutma amacı ve bunları yönetim modeli önemlidir. Madencilik yapan veya değişim aracı olarak kullanan işletmeler bu varlıkları kısa veya uzun vadeli yatırım olarak elde tutmak amacıyla edinmezler. Madencilik yapan işletme için ödül olarak alınan kripto araç verdiği hizmetin karşılı̆̆ 1 faaliyet geliridir. Alım satımını yapan işletme açısından kripto araç emtia veya konsinye varlıktır. Alım satımda kripto araç kullanan işletmeler için ise ödeme veya tahsilat aracıdır. Bu itibarla kripto araçların alım satımını yapan işletmeler için emtia, diğerleri için ise finansal varlık olarak sınıflandırılması uygun olacaktır. Bu itibarla bu araçların nakit benzeri döviz aracı olarak sınıflandırılmaları mümkündür.

$\mathrm{Bu}$ araçların tam olarak likit varlıklar oldukları söylenemez. Ancak konvertibilitesi düşük pek çok döviz için de aynı durum sözkonusudur. Aynı şekilde değerlerindeki değişim riski yüksek pek çok döviz mevcuttur. Dolayısıyla likiditesinin düşük olması ve değişim riskinin yüksek olması kripto araçların nakit benzeri olarak nitelendirilmemesi için yeterli değildir. Diğer taraftan bu araçların likiditesinin düşük ve değerindeki değişim riskinin yüksek olduğunun finansal tablo açıklama ve dipnotlarında belirtilmesi gereklidir.

\subsubsection{Madencilik Yaparak Kripto Para Elde Eden İşletme}

Madencilik yapan işletme kendi bilgisayarlarını Blokchain sisteminin kullanımına açarak hizmet etmektedir. Bu haliyle sistem tarafindan verilen ödül faaliyet geliridir. Bu faaliyetle ilgili direkt işçilik giderleri ile amotisman, elektrik ve diğer hizmet üretim giderlerinden sistematik olarak aktarılacak paylar hizmetin maliyetini oluşturur. Diğer taraftan, dönem sonunda hasılat elde edilmemiş olan hizmet maliyetleri UMS 2 Stok Standardı çerçevesinde "Tamamlanmış yada Tamamlanmamış Hizmet Maliyetleri" olarak bilançoda raporlanmalıdır.. UMS 2 Stoklar Standardı normal maliyet sistemini benimsemiştir. $\mathrm{Bu}$ yüzden sabit hizmet üretim giderlerinin kripto araç maliyetlerine yansıtılmasında normal kapasitenin kullanılması ve dağıtılmayan sabit giderlerin satışların maliyeti arasında gösterilmesi gereklidir.

\subsubsection{Tahsilat veya Ödeme Aracı Olarak Kullanan İşletme}

Sattığı mal veya hizmet karşıllı̆ında Bitcoin gibi bir kripto aracı alan işletme bu aracın likiditesinin düşük ve değerindeki değişim riskinin yüksek olduğunu bilerek bunu bir tahsilat aracı olarak kabul etmiştir. Satıştan elde ettiği kripto aracı nakit benzeri finansal varlıkları arasına alacak ve burada raporlayacaktır. $\mathrm{Bu}$ araçların konvertibilitesinin düşük ve değerindeki değişim riskinin yüksek olduğuna ilişkin açıklamaları finansal tablo açıklayıcı notlar ve dipnotlarında belirtecektir. Satış ve kripto aracın elde edilmesiyle ilgili verilen komisyon ve nakde çevirme giderlerini pazarlama satış dağıtım giderleri arasına alacak ve raporlayacaktır. Vadeli satış durumunda satış ile tahsilat tarihleri arasındaki kur farklarını UMS 21 doğrultusunda kambiyo kar/zararı olarak kayıtlara alacaktır. Değerleme gününde de elindeki kripto araçları yine UMS 21 doğrultusunda değerleyecek ve artış/azalışları kambiyo kar/zararı olarak kaydedecektir. $\mathrm{Bu}$ işletme geçerli para birimiyle raporlama yapacaktır. Geçerli para birimi: İşletmenin faaliyet gösterdiği temel ekonomik çevrenin para birimidir (UMS 21 md.8). Kripto araçlarını ve bunun üzerinden kayıtlı alacak ve borçlarını UMS 21 md. 8'de tanımlanan hemen teslim halindeki geçerli olan döviz kuru olan geçerli (spot) kur üzerinden değerleyecektir. Her ne kadar kripto araçların alınıp satıldığ 1 piyasalar, kambiyo veya menkul kıymetler borsaları gibi yapılandırılmış piyasalar olmasa da bu araçların da 
borsaları vardır. $\mathrm{Bu}$ piyasalarda kripto araçların değerleri arasında farklılıklar olması durumunda işlem hacmi yüksek piyasalardaki değerlerin ortalamaları kullanılabilir. Yapılan değerleme sonucunda değer artış/azalışlarını kambiyo kar/zararları arasında raporlayacaktır.

Alımları karşılığında ödemelerini kripto araçlarla yapan işletme aldığı varlığın değerini kripto aracın o andaki kripto araç kuruyla geçerli para birimine çevirerek belirleyecek, kripto araçla ilgili işlem maliyetleri ve komisyonları da ilgili varlığın maliyetine aktaracaktır. Vadeli alımlarda kur farkı ortaya çıkmışsa UMS 23 Borçlanma Maliyetleri Standardı doğrultusunda varlık elde edildikten sonra ortaya çıkan vade farkları dönem giderlerine aktaracaktır. Elinde tuttuğu kripto araçlar ile kripto araç üzerinden alacak ve borçlarında meydana gelen kur farklarını UMS 21 Kur Değişiminin Etkileri Standardı doğrultusunda değerleyecek ve kambiyo kar/zararı olarak raporlayacaktır.

\subsubsection{Kripto Araçların Alım Satımını Yapan İşletme}

Faaliyet konusu kripto araçların alım satımı olan işletmeler menkul kıymet yatırım ortaklıklarına, aracı kurumlara ve döviz bürolarına benzetilebilir. SPK mevzuatına göre menkul kıymet yatırım ortaklıkları sermaye piyasası araçları ile altın ve diğer kıymetli varlıklardan oluşan bir portföyün işletilmesi ve portföy hisselerinin alım satımını yapan işletmelerdir. Bu itibarla kripto araçlar porföye dahil edilebilse de bu işletmelerin esas faaliyet konusu kripto araç alım satımı yapmak değildir. Bu itibarla kripto araç ticareti yapan işletmelerin menkul kıymet yatırım ortaklıklarına benzetmek mümkün görülmemektedir.

Aracı kurumlar esas itibariyle kendi mülkiyetinde olmayan menkul k1ymetleri komisyon karşılığında müşterileri adına alıp satmaktadır. Bu itibarla kendi mülkiyetinde olmayan kripto araçların ticaretinde aracılık yapan işletmeleri aracı kurumlara benzetebiliriz. $\mathrm{Bu}$ işletmelerde satılmak üzere bulunan kripto araçlar konsinye varlıklar olarak kaydedilip raporlanmalıdır. $\mathrm{Bu}$ işletmelerin faaliyet gelirleri elde ettikleri komisyonlardan; faaliyet giderleri ise bu amaçla maruz kaldıkları harcama veya borçlanmalardan oluşmaktadır.

Kendi mülkiyetinde bulunan kripto araçların ticaretini yapan işletmeler döviz bürolarına benzetilebilir. Böylece bu işletmeler kripto araçlarını ilk giriş, dönem sonu değerleme ve işletmeden çıkışında, UMS 2 Stoklar Standardı doğrultusunda sınıflandıracak ve raporlayacaktır. Bunların satış gelirleri ve kur farkları hasılat olarak kayıtlara alınacaktır.

\section{SONUÇ VE ÖNERILER}

Dünyada ve ülkemizde para, menkul kıymet yada emtia olduğu konusunda tartışmaların devam ettiği kripto araçlar günümüzde ticari hayata girmiştir. Muhasebenin temel amacı bilgi kullanıcılarına işletmenin durumunu gerçeğe uygun şekilde sunmak olduğundan bu araçların kaydedilmesi, değerlemesi ve finansal tablolarda sunum ve açıklamaları konularının tartışılması ihtiyacı ortaya çıkmıştır. Bu yüzden çalışmamızda bu varlıkların madenciliğini, ticaretini yapan ve bunları değişim aracı olarak kabul eden işletmeler açısından bunların kaydedilmesi ve finansal tablolara alınması konuları ele alınmıştır. $\mathrm{Bu}$ amaçla Muhasebe Sistemi Uygulama Genel Tebliğleri ve Uluslararası Muhasebe/Finansal Raporlama Standartları doğrultusunda değerlendirmeler yapılmıştır. 
Özel donanımlarıyla Blokchain yazılımlarını çalıştıran madenciler bir taraftan Bitcoin kazanırken; diğer taraftan dağıtık ağın gücüne güç katma ve koruyup geliştirme konusunda sisteme hizmet etmektedirler. $\mathrm{Bu}$ yönüyle madencilik işletmelerini hizmet işletmelerine benzetebiliriz. $\mathrm{Bu}$ hizmet karşılığ Böylece elde edilen ödüller satış gelirlerine alınırken; bunun için katlanılan maliyetler de hizmet üretim maliyetleri olacaktır. Bu çerçevede sunulan hizmetlerin maliyeti; direkt işçilik giderleri ve hizmet üretimiyle doğrudan ilişkili elektrik ve amortisman gibi hizmet üretim giderlerinden sistematik bir şekilde dağıtılan tutarlardan oluşacaktır. Ayrıca elde edilen kripto araçlar, günümüzde kolaylıkla Türk Lirasına çevrilebildiği de düşünüldüğünde, "Diğer Hazır Değerler" arasında raporlanabilecektir.

MSUGT açısından kripto araçların dönem sonu değerlemesi VUK 280. madde hükmüne göre borsa rayici ile yapılacak ve değerleme farkları kambiyo kar/zararı olarak kayıtlara alınacaktır. Bununla birlikte yasal otoritenin kripto araç borsalarıyla ilgili düzenleme yapma gereği de ortaya çıkacaktır. Diğer taraftan madencilik faaliyetinin sonucu elde edilen kripto araçlar yasal otorite tarafindan emtia olarak kabul edilirse alım satımında KDV uygulanması gerekecektir. Ayrıca her durumda elde edilen gelirler dolayısıyla gelir/kurumlar vergisi doğacaktır.

Uluslararası Muhasebe Standartları açısından da madencilik hizmet faaliyeti olarak değerlendirilebilir. Kazanılan kripto araçlar faaliyet geliri ve bu hizmetle ilişkilendirilebilen giderler faaliyet gideri olarak kayıtlara alınır. Ayrıca dönem sonunda hasılat elde edilememiş olan hizmet maliyetleri, UMS 2 Stok Standardı çerçevesinde satış gerçekleşinceye kadar stok olarak bilançoda raporlanmalıdır. UMS 2 Stoklar Standardı normal maliyet sistemini benimsemiştir. $\mathrm{Bu}$ yüzden sabit hizmet üretim giderlerinin kripto araç maliyetlerine yansıtılmasında normal kapasitenin kullanılması ve dağıtılmayan sabit giderlerin satışların maliyeti arasında gösterilmesi gereklidir.

Sattığ1 mal veya hizmet karşılığında kripto araç alan işletme bu aracın likiditesinin düşük ve değerindeki değişim riskinin yüksek olduğunu bilerek bunu bir tahsilat aracı olarak kabul etmiştir. Satıştan elde ettiği kripto aracı diğer hazır değerler gibi nakit benzeri finansal varlıkları arasına alacak ve burada raporlayacaktır. Satış ve kripto aracın elde edilmesiyle ilgili verilen komisyon ve nakde çevirme giderlerini pazarlama satış dağıtım giderleri arasına alacak ve raporlayacaktır.

MSUGT doğrultusunda alımları karşılığında ödemelerini kripto araçlarla yapan işletme aldığı varlığın değerini kripto aracın o andaki kur ile Türk Lirasına çevirerek belirleyecek, kripto araçla ilgili işlem maliyetleri ve komisyonları da ilgili varlığın maliyetine ekleyecektir. Elinde tuttuğu kripto araçlardaki kur farklarını, kripto araç üzerinden alacak ve borçlarını da yine VUK'un 280. maddesi doğrultusunda değerleyecektir.

UFRS kapsamında bu işletmeler elde ettiği kripto araçları nakit benzeri finansal araç kaydedip raporlayacaktır. $\mathrm{Bu}$ araçların konvertibilitesinin düşük ve değerindeki değişim riskinin yüksek olduğuna ilişkin açıklamaları finansal tablo açıklayıcı notlar ve dipnotlarında belirtecektir. Vadeli satış durumunda satış ile tahsilat tarihleri arasındaki kur farklarını UMS 21 Kur Değişiminin Etkileri Standardı doğrultusunda kambiyo kar/zararı olarak kayıtlara alacaktır. Değerleme gününde elindeki kripto araçları yine UMS 21 doğrultusunda değerleyecek ve artış/azalışları kambiyo kar/zararı olarak kaydedecektir. Bu işletme geçerli 
para birimiyle raporlama yapacaktır. Kripto araçlarını ve bunun üzerinden kayıtlı alacak ve borçlarını geçerli (spot) kur üzerinden değerleyecektir. Alımları karşılığında ödemelerini kripto araçlarla yapan işletme aldığı varlığın değerini kripto aracın o andaki kripto araç kuruyla geçerli para birimine çevirerek belirleyecek, kripto araçla ilgili işlem maliyetleri ve komisyonları ilgili varlığın maliyetine yansitacaktır. Vadeli alımlarda kur farkı ortaya çıkmışsa UMS 23 Borçlanma Maliyetleri Standardı doğrultusunda varlık elde edildikten sonra ortaya çıkan vade farkları dönem giderlerine aktaracaktır. Elinde tuttuğu kripto araçlar ile kripto araç üzerinden alacak ve borçların meydana gelen kur farklarını UMS 21 Kur Değişiminin Etkileri standardı doğrultusunda değerleyecek ve kambiyo kar/zararı olarak raporlayacaktır.

Faaliyet konusu kripto araçların alım satımı olan işletmeler aracı kurumlara ve döviz bürolarına benzetilebilir. Aracı kurumlar esas itibariyle kendi mülkiyetinde olmayan menkul kıymetleri komisyon karşılığında müşterileri adına alıp satmaktadır. Bu işletmelerde satılmak üzere bulunan kripto araçlar konsinye varlıklar olarak kaydedilip raporlanmalıdır. Bu işletmelerin faaliyet gelirleri elde ettikleri komisyonlardan; faaliyet giderleri ise bu amaçla maruz kaldıkları harcama veya borçlanmalardan oluşmaktadır. Kendi mülkiyetinde bulunan kripto araçların ticaretini yapan işletmelerin faaliyet gelirleri alım satımdan elde ettikleri gelirler ve giderleri ise bunun için katlandıkları harcama ve borçlanmalardan oluşur.

$\mathrm{Bu}$ işletmeler MSUGT açısından kripto araçlarını VUK 280. madde hükmü doğrultusunda değerleyeceklerdir. Dönem sonunda kripto araçların değeri tespit edildikten sonra satılan döviz maliyeti bulunarak kâr hesaplanacaktır.

UMS açısından ise bu işletmeler kripto araçlarını ilk giriş, dönem sonu değerleme ve işletmeden çıkışında, UMS 2 Stoklar Standardı doğrultusunda sinıflandıracak ve raporlayacaktır. Bunların satış gelirleri ve kur farkları hasılat olarak kayıtlara alınacaktır.

$\mathrm{Bu}$ çalışma kripto araçları çeşitli şekillerde kullanan ve elinde bulunduran işletmelerin muhasebeleştirme ve finansal tablolarda sunum konusundaki ihtiyaçlarına yönelik, belirli varsayımlar üzerinden yapılmış yorumlardan ibarettir. Özellikle bu araçların para, menkul kıymet veya emtia olduğuna dair ortak bir görüş oluşmadan veya düzenleme yapılmadan bu çalışmadaki yorumların havada kalacağı düşünülebilir. Diğer taraftan bu araçlarla ilgili olay ve işlemlerin muhasebeleştirilmesi bir ihtiyaç olarak ortadadır. Çalışma bu ihtiyaca yönelik olarak yapılmıştır.

Gelecekte Blokchain uygulamaları üzerinden yapılan sözleşmelerin ve para transferleri yapan tarafların bu işlem ve olaylarını muhasebe ve finansal tablolarına aktarılması konusunda çalışmalar yapılabilir. Diğer taraftan bağımsız denetim çalışmalarında sözleşmelerin, çalışma kâğıtlarının ve denetim raporlarının bu teknoloji ile saklanması tartışılabilir. 


\section{KAYNAKLAR}

Baur, Dirk G. - Hong, KiHoon (2015), "Bitcoin: Currency or Asset?", SSRN Electronic Journal, January, pp.1-21.

Boomer, Gary (2016), "Blockchain: What it is, and why it matters to CPAs", Accounting Today, October, p.26.

Brandvold, Morten - Molnár, Peter - Vagstad, Kristian - Valstad, Ole Christian Andreas (2015), "Price discovery on Bitcoin exchanges", Journal of International Financial Markets, Institutions \& Money, 36, pp.18-35

Dai, Jun - Vasarhelyi, Miklos A. (2017), "Toward Blockchain-Based Accounting and Assurance", Journal of Information Systems, Vol. 31, No. 3, Fall, pp. 5-21

Dinler, Zeynel (2003), İktisada Giriş, Ekin Kitabevi, Bursa.

Dwyer, Gerald P. (2015), "The Economics of Bitcoin and Similar Private Digital Currencies", Journal of Financial Stability, 17, pp. 81-91.

Lee, David Kuo Chuen - Nian, Lam Pak (2015), Handbook of Digital Currency Bitcoin, Innovation, Financial Instruments, And Big Data, Elsevier, London.

Leon, Daniel Conte de - Stalick, Antonius Q. - Jillepalli, Ananth A. - Haney, Michael A. Sheldon, Frederick T. (2017) "Blockchain: properties and misconceptions", Asia Pacific Journal of Innovation and Entrepreneurship, Vol. 11, Issue: 3, pp.286-300.

Mishkin, Frederic S. - Serletis, Apostolos (2004), The Economics Of Money, Banking And Financial Markets, Pearson, Toronto, (Nazım Engin - Şercin Şahin - Serkan Çiçek Çiğdem Boz), Para, Bankacılık ve Finansal Piyasalar İktisadı, Akademi Yayıncılık, 2011, İstanbul.

Nakamoto, Satoshi (2008) "Bitcoin: A Peer-to-Peer Electronic Cash System", https://bitcoin.org/bitcoin.pdf (17.01.2018).

Ram, Asheer - Maroun, Warren - Garnett, Robert (2016) "Accounting for the Bitcoin: Accountability, Neoliberalism and a Correspondence Analysis", Meditari Accountancy Research, Vol. 24 Issue: 1, pp.2-35.

Raiborn, Cecily - Sivitanides, Marcos (2015), “Accounting Issues Related to Bitcoins”, The Journal of Corporate Accounting \& Finance, January/February, pp.25-34.

Seng, Tan Boon - Yew, Low Kin (2015), "Bitcoin: Its Economics and Financial Reporting", Australian Accounting Review, Vol. 27(2), pp.220-227.

Şen, İsmihan (2005), Menkul Kıymet Gelirlerinin Tam Mükellef Gerçek Ve Tüzel Kişiler Yönünden Vergilendirilmesi $\mathrm{Ve} \mathrm{Bu}$ Gelirler Üzerindeki Vergi Yüklerinin Karşılaştırılması, Uzmanlık Yeterlilik Tezi, Türkiye Cumhuriyet Merkez Bankası Muhasebe Genel Müdürlüğü Ankara. 
Theodosis, Mourouzis - Filipou, Chrysostomos (2017) "The Blockchain Revolution: Insights from Top-Management", https://arxiv.org/abs/1712.04649 (21.05.2018).

Usta, Ahmet - Doğantekin, Serkan (2017), Blokchain 101, Kapital, İstanbul.

Yüksel, A. Ebru Bozkurt, (2015), “Elektronik Para, Sanal Para, Bitcoin ve Linden Doları'na Hukuki Bir Bakış”, İstanbul Üniversitesi Hukuk Fakültesi Mecmuası, C. LXXIII, S. 2, ss. $173-220$.

https://coinmap.org, 21.05.2018

https://techterms.com/definition/p2p, 17.01.2018

https://www.memurlar.net/haber/716053/bitcoin-yatirimcilarinin-isyani-sosyal-medyayadamgasini-vurdu.html, 20.12.2017

https://poloniex.com/exchange\#usdt_btc, 05.01.2018

https://www.worldcoinindex.com, 25.12.2017

https://mbs.edu/getattachment/fircg/FIRCG-2016/Papers/8-Adrian-2c-KiHoonBitcoin-Bauret-al-2015-P.pdf, 19.12.2017

https://poloniex.com/exchange\#btc_bch 05.01.2018

https://www.turkiye.gov.tr/doviz-kurlari 05.01.2018

https://www.memurlar.net/haber/716053/bitcoin-yatirimcilarinin-isyani-sosyal-medyayadamgasini-vurdu.html, 20.12.2017

https://bitcoincharts.com/bitcoin, 19.12.2017

https://coinmarketcap.com, 22.05.2018

www.tdk.gov.tr, 05.01.2018

6362 Sayılı Sermaye Piyasası Kanunu (2012), T.C. Resmi Gazete, 28513, 30 Aralık 2012.

6102 Sayılı Türk Ticaret Kanunu (2011), T.C. Resmi Gazete, 27846, 14 Şubat 2011.

213 Say1lı Vergi Usul Kanunu (1961), T.C. Resmi Gazete, 10703, 10704 ve 10705, 10 Ocak 1961, 11 Ocak 1961 ve 12 Ocak 1961.

3065 Sayılı Katma Değer Vergisi Kanunu (1984), T.C. Resmi Gazete, 18563, 25 Ağustos 1984.

193 Sayılı Gelir Vergisi Kanunu (1960), T.C. Resmi Gazete, 10700, 31 Aralık 1960.

5520 Sayılı Kurumlar Vergisi Kanunu (2006), T.C. Resmi Gazete, 26205, 21 Haziran 2006. 
1567 Sayılı Türk Parasını Koruma Kanunu (1930), T.C. Resmi Gazete, 1433, 20 Şubat 1930.

Muhasebe Sistemi Uygulama Genel Tebliği I (1992), T.C. Resmi Gazete, Mükerrer 21447, 26 Aralık 1992.

Finansal Raporlamaya İlişkin Kavramsal Çerçeve Hakkında Tebliğ (2011), T.C. Resmi Gazete, 27828, 27 Ocak 2011.

TMS 2 Stoklara İlişkin Türkiye Muhasebe Standardı (2005), T.C. Resmi Gazete, 25701, 15 Ocak 2005.

TMS 7 Nakit Akış Tablolarına İlişkin Türkiye Muhasebe Standardı Hakkında Tebliğ (2005), T.C. Resmi Gazete, 25704, 18 Ocak 2005.

TMS 32 Finansal Araçlar: Sunuma İlişkin Türkiye Muhasebe Standardı Hakkında Tebliğ ( 2006), T.C. Resmi Gazete, 26330, 26 Ekim 2006.

TFRS 9 Finansal Araçlar Standardına İlişkin Türkiye Finansal Raporlama Standardı Hakkında Tebliğ (2017 sürümü) (2017), T.C. Resmi Gazete, 29953, 19 Ocak 2017. 